\title{
Attentional Biases and Vulnerability to Depression
}

\author{
Myriam Gallardo Pérez \\ University of Jaume I
}

Amparo Belloch Fuster
University of Valencia

\author{
Rosa $\mathrm{M}^{\mathrm{a}}$ Baños Rivera* \\ University of Valencia \\ $\mathrm{M}^{\mathrm{a}}$ Ángeles Ruipérez Rodríguez \\ Universily of Jaume I
}

\begin{abstract}
This study was designed to examine selective processing of emotional information in depression. It focuses on possible attentional biases in depression, and whether such biases constitute a cognitive vulnerability factor to suffer from the disorder or, on the contrary, they reftect a feature associated exclusively with the clinical level of depression. 81 participants were included in the study: 15 with a diagnosis of Major Depression; 17 were diagnosed as Dysthymia: 11 participants scored over 18 in the Beck Depression Inventory (Beck, Rush, Shaw, \& Emery, 1979); 15 participants, in whom a sad mood state was induced by an experimental mood induction (Velten technique + music, or biographical recall + music); and 23 participants as a normal-control group. All participants were presented with the emotional Stroop task. The data indicated that attentional bias was only present in the group of patients with Major Depression, so it does not seem to be a cognitive vulnerability factor for this disorder.

Key words: depression, valnerability, attentional biases, Stroop task
\end{abstract}

\begin{abstract}
En este trabajo se examina el procesamiento selectivo de la información emocional en depresión. Los objetivos se centran en comprobar, en primer lugar, si existen o no sesgos atencionales en la depresión y, en segundo lugar, si estos sesgos constituyen un factor de vulnerabilidad cognitiva a padecer el trastorno o si, por el contrario, reflejan una característica asociada exclusivamente al nivel clínico de depresión. Los participantes fueron 15 pacientes con diagnóstico de Depresión Mayor, 17 pacientes con diagnóstico de Distimia, 11 personas con una puntuación superior a 18 en el Irventario de Depresión de Beck (Beck, Rush, Shaw y Emery, 1979), 15 personas a las que se indujo un estado de ánimo triste (técnica Velten con música, o recuerdo autobiográfico con música) y 23 personas "controles". Todos los sujetos cumplimentaron la tarea Stroop emocional. Los datos indicaron que el sesgo atencional sólo se manifestaba en el subgrupo de Depresión Mayor, por lo que no parece constituir un factor de vulnerabilidad cognitiva para la depresión. Palabras clave: depresión, vulnerabilidad, sesgos atencionales, tarea Stroop
\end{abstract}

This study is part of a research supported by the DGICYT (PS92-0158).

* Correspondence concerning this article should be addressed to Dr. Rosa María Baños. Departamento de Personalidad. Facultad de Psicología. Avda. Blasco Ibáñez. 21. 460 to Valencia (Spain). E-majli banos@uves 
One of the basic assumptions of cognitive-experimental approaches to psychopatholgy of emotional disorders is that there are differences in the way emotional information is processed, depending on whether or not there is pathology. However, one of the most important issues stil] to be settled is whether such cognitive biases constitute a vulnerability factor for these disorders or, on the contrary, they are part of their clinical features. Beck's cognitive model (1967, 1976, 1987), based on the concept of "schemata," is the starting point in most of these studies. According to Beck, the schemata used by depressed people are negative, and lead to selective filtering out of positive information and to cxaggeration of negative information. Beck's model predicts that mood-congruent biases will be revealed in all stages of processing (perception, encoding, attention, storage, and recall).

Attention, in particular, is one of the cognitive processes affected in many psychological disorders. In depression. distractibility and difficulty in concentrating are two of the most frequent complaints reported by patients, and they are among the symptons of the "Diagnostic and Statistical Manual of Mental Disorders, $4^{\text {h }}$ edition" (American Psychiatric Association, 1994) criteria for the diagnosis of major depression and dysthymia. In cognitive psychology, when referring to attentional biases, psychologists do not mean general distractibility, but a change in the direction of the focus of attention, so people are more aware of a part, or a ccrtain aspect, of their environment (Williams, Watts, MacLcod, \& Mathews, 1988, 1997). In anxiety disorders, it has been demonstrated that patients show attentional bias towards threatening information that is congruent with the disorder.

In the body of literature regarding attentional biases, two main strategies have been used: a) showing how the tendency to pay attention to certain environmental stimuli facilitates the subjects' performance in the tasks, and b) showing how the same trend deteriorates performance. The Emotional Stroop Color-Naming Task, which is probably the most widely tool used in the study of attentional biases, has become the main experimental paradigm in literature about cognition and emotion and it belongs to the second strategy. In the emotional Stroop task, the subject is shown words whose emotional content represents the core themes that characterize the disorder under study (for example, threat for anxiety, sadness and hopelessness for depression). This emotional content has a disruptive elfect on the individual's cognitive functioning because it is related to the theme of the person's disorder (Williams et al., 1997). Attentional bias is revealed by the interference effect of the Stroop task (Stroop, 1935), produced by the competition between the task required (naming the color) and the automatic and preconscious processing of the printed words (attentional bias). The time subjects spend responding to the stimuli is the dependent variable measured in the Stroop task. Numerous studics that have used the Stroop task have shown that the response time in naming the color in which an emotional word is printed is greater in those persons who are aflected by an emotional disorder (Williams et al, 1997). Most rescarchers assume that the effect caused by the emotional stimuli in lasks such as the Stroop is due to the stimuli capturing the person's attentional resources.

Data supporting the existence of attentional bias lowards emotional information are much sounder in anxiety than in depression (Dalgleish \& Wats, 1990; MacLeod, Mathews, $\&$ Tata, 1986). Several studies have used the Stroop task to investigate processing biases in generalized anxicty disorder (c.g., Martin. Williams, \& Clark, 1991; Mathews, Mogg, Kentish, \& Eysetick, 1995: Mogg. Bradley, Williams, \& Mathews, 1993), post-traumatic stress disorder (Cassiday, McNally, \& Zcillin, 1992; Kaspi, McNally, \& Amir, 1995; McNally et al., [994; MeNally, English, \& Lipke, 1993; McNally, Rienmann, \& Kim, 1990), obssesive-compulsive disorder (Foa \& McNally, 1986; Lavy, van Oppen, \& van den Houl, 1994), social phobia (Hope, Rapec, Heimberg, \& Dombeck, 1990; Mattia, Heimberg, \& Hope, 1993), and simple phobias, such as spider phobia (Lavy, van den Hout, \& Amtz, 1993; Walts, McKenna. Sharrock, \& Trezise, 1986) and snake phobia (Mathows \& Scbastian, 1993). It has been found that people affected by these disorders show significantly more interference in color-naming threatening words, and words related to their disorder, than ncutral words. Regarding depression, not only are there fewer studies, but also, the differential results are confusing and not very conclusive (Carter, Maddock, \& Magliozzi, 1992; Gotlib \& Cane, 1987; Gotlib \& McCann, 1984; Hill \& Dutton, 1989; Hill \& Knowles, 1991; Klieger \& Cordner, 1990; Mogg at al., 1993; Segal \& Vella, 1990).

The purpose of this study was to investigate whether or not there are attentional biases in depression. If so, depressed individuals would display selective attention towards the negative aspects of the information they are shown, but this would not occur with the individuals who had no emotional disorder. Another aim was to find out whether these differences constitute at cognitive vulnerability factor for the disorder or, on the contrary, they reflect a feature linked exclusively to the clinical level of depression. It is possible that attentional biases are simply the result of a sad or depressed mood, or that they must be accompanied by other signs and symptoms that are typical of depression (without reaching clinical significance) in order to appear. Bearing these goals in mind, the exploratory hypotheses in this study were as follows:

1. If there is attentional bias in depressive disorders, the individuals with a clinical diagnosis of depression (groups of Major Depression - MD - and Dysthymia - Dy), compared to normal individuals (control group), will be significantly slower in color-naming depression-related negalive words than positive ones.

2. With regard to the vulnerability issue:

2.1) If attentional bias does not constitute a vulnerability factor, but is another feature of depressive disorders, then only the clinical groups (MD and Dy), compared to normal individuals (control group), to participants with a sad mood 
(induction group), and to those with a subclinical level of depression (subclinical group), will be significantly slower in color-naming depression-related negative words than positive ones.

2.2) If attentional bias is a vulnerability factor related not only to mood, but requiring the presence of other signs and symptoms of depression (such as motivation, selfvaluation, etc.) in order to appear, then individuals with a subclinical level of depression (subclinical group), assessed by questionnaires such as the Beck Depression Inventory (Beck, Rush, Shaw, \& Emery, 1979), and depressed individuals (MD and Dy groups) will be significantly slower in color-naming negative words than positive ones, compared to normal and sad participants (control and induction groups).

2.3) If attentional bias is simply the result of a sad mood, all participants except the normal group (control group) will be significantly slower in color-naming depression-related negative words than positive ones.

\section{Method}

\section{Participants}

A total of 81 participants were tested. Forty-nine were undergraduate students from different areas, excepting Psychology, recruited by means of an advertisement that asked for volunteers to participate in a psychological study in return for a reward (2,000 pesetas); they had no psychological disorder, either past or present, at the moment of the study. The remaining 32 were patients from the Liria Unil of Mental Health (Unidad de Salud Mentai de Lliria), a public mental-health facility to which they had been referred by the general practitioner. There were 52 women and 29 men whose ages ranged from 15 to 55 years $(M=28.29$, $S D=12.35$ ). We distributed the participants into 5 groups:
1) Major Depression (MD): 15 patients (6 men, 9 women) whose main diagnosis was major depression, according to the "Diagnostic and Statistical Manual of Mental Disorders, $3^{\text {rl }}$ edition" (American Psychiatric Association, 1987) criteria. (At the timc of the study, the Spanish edition of the DSMIV was not available.)

2) Dysthymia (Dy): 17 patients ( 5 men, 12 women) whose main diagnosis was dysthymia, according to DSMIII-R criteria.

3) Subclinical: 11 individuals ( 4 men, 7 women) who obtained a score $\geq 18$ in the Beck Depression Inventory (BDi; Beck, Rush, Shaw, \& Emery, 1979), but could not be described as presenting a clinical depressive disorder because they had not sought psychological assistance at any point in their lives.

4) Induction: 15 individuals ( 7 men, 8 women) with no clinical diagnosis, who underwent a mood induction procedure to induce a sad mood in them.

5) Control: 23 individuals ( 7 men, 16 women) with no emotional disorder, who underwent no experimental mood induction, and whose BDI scores were not clinically significant $(\leq 13)$.

Participants who answered the advertisement were assigned to the subclinical, induction, and control groups. Participants of the induction and control groups were randomly assigned to their groups. All individuals with a score $\geq 18$ in the BD] were automatically assigned to the subclinical group, because of methodological and ethical issues. The final composition of the sample is shown in Table 1.

\section{Procedure}

Clinical sample. The day the patients came to the Mental Health Unit, they received a DSM-III-R diagnosis by an expert clinician (psychiatrist or psychologist). If they met MD or Dy criteria, they had a structured interview, which

Table 1

Number of Paricipants in each Group by Sex; and Age Range (Means and Standard Deviations) of each Group

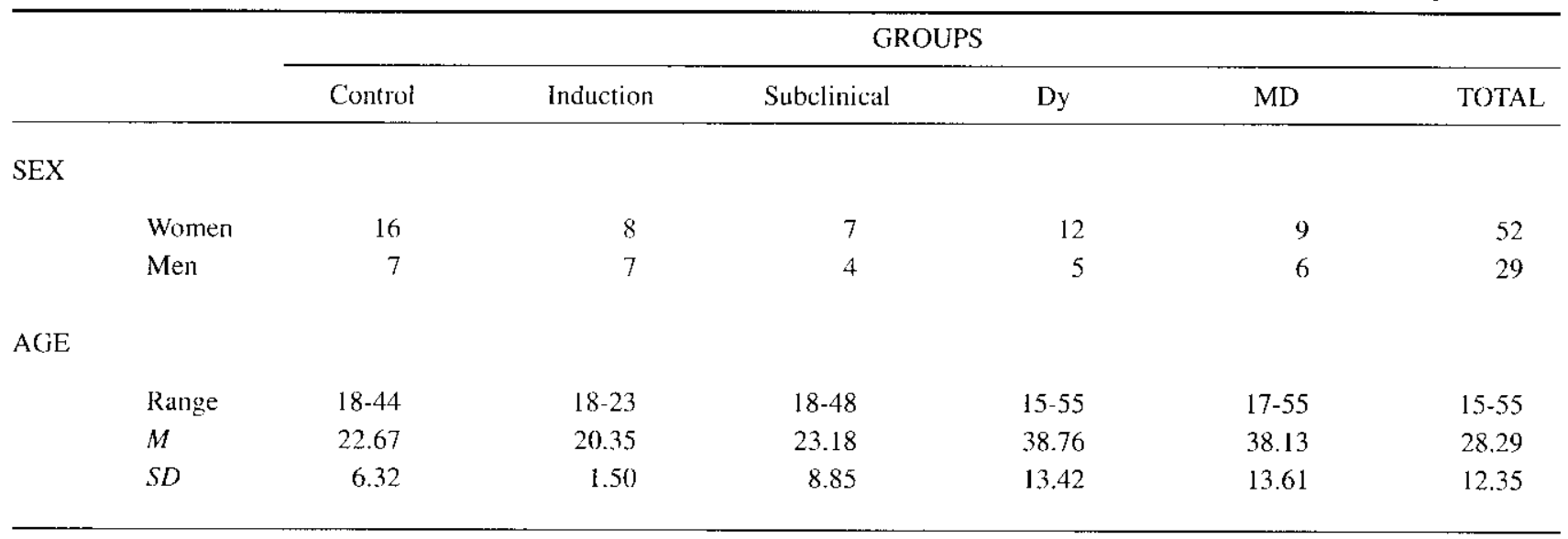

Note. $\mathrm{Dy}=$ dysthymia; $\mathrm{MD}=$ major depression. 
included demographic data and a clinical record, with the psychologist of the Unit (M.A.R.). Only those cases in which there was inter-judge agreement on the diagnosis were included. If the patients met the remaining selection criteria (voluntary consent, not having past or present history of alcoholism, substance abuse, or severe organic disease, not receiving medication) they were scheduled to complete the $\mathrm{BDI}$ and the State-Trait Anxiety Inventory (STAI; Spielberger; 1983), and to perform the Stroop task on the following day.

Nonclinical sample. The experimental session started with a screening interview to make sure the individuals were free from any mental disorder and that they had not had any in the past. Next, they filled in the psychometric measures (BDI, STAI). Participants did not know either the real purpose of the research or the group to which they had been assigned, nor were they familiar with the mood induction procedures or the Stroop task. After completing the questionnaires, the subclinical and control groups performed the Stroop task, and participants from the induction group were randomly assigned to the mood induction procedures. Two procedures were used (equal number of subjects in each one): reading Velten sentences while listening 10 a picce of music, and recalling a biographic memory while listening to a piece of music. Both procedures have proved to be effective in inducing different moods (Garcia-Palacios, 1995; Kenealy, 1986: Larsen \& Sinnet, 1991; Marin, 1990b; Martin, Argyle, \& Crossland, 1990). To apply the Velten procedure, we designed a list of 10 self-referent sentences, similar to those used by Velten in 1968. (For example, "I think life is empty and meaningless": "Only bad things happen to me"; "Nobody loves me"; etc.) Participants were required to read the sentences slowly to themselves, as long as the induction lasted ( 10 minutes), paying attention to their emotional content, and thinking about the sentences as though they referred specifically to them. The procedure of recalling a memory consisted of asking the subjects to recall any sad biographic memory and to think about it, trying to bring back the feelings, thoughts, and emotions that surrounded the event. As the subjects read the Velten sentences or recalled a memory, they listened to a 10 minute piece of Barber's "Adagio for Strings." The instructions were recorded on a tape. Both mood induction procedures (Velten + Music, and Recall + Music) were effective in changing the participants" mood in the expected direction: the change in the subjective appraisal of their sad mood, measured by means of a visual analogical scalc ranging from 0 to 100 , was above $15 \%$. After the induction, the participants performed the Stroop task.

\section{Materials}

The Stroop task consisted of three conditions: trial. depression, and clation. Five DIN- $\Lambda 4$ cards $(21 \times 29.7 \mathrm{~cm}$. were designed, with 72 words arranged in 6 columns of 12 words each. The cards were printed in capital letters using red, bluc,-yelow, and green. Words were distributed so that neither color nor word were placed in adjacent locations on the card. The trial condition consisted of rows of zeros $(00000)$, considered neutral stimuli. The emotional Stroop condition consisted of sad-content adjectives (depression) and happy-content adjectives (elation). These stimuli were the same as those used in the study by Ruiperez and Belloch (1997), in which the words were selected in two phases. First, a 200 -word list was composed, using words from published literature that had employed traits with depressive content, and from various instruments for measuring depression. Then, ten expert judges (clinical psychologists and psychiatrists) assessed the appropriateness of the traits to describe negative and positive personal characteristics. The final selection was based on the traits that obtained a score of 6 or over in one category, and 3 or under in the other. Because in Spanish, adjectives have a masculine and a feminine form, we prepared two cards for each emotional condition, so the stimuli would be in accordance with the participant's sex. First, the trial card was presented to all participants. The presentation order of the remaining 2 cards was randomized, with the only condition that half of the subjects of every group were presented with the depression card after the trial card and the other half was presented with the elation card. Time was measured in milliseconds, using a chronometer. The pool of words, and their English translation, is shown in Table 2.

\section{Results}

\section{Demographic variables}

The only statistical difference among groups in demographic variables was in the variable age: the MD and Dy groups were significantly different and older than the other groups, $p<.05$. The distribution of both sexes among groups was similar, $\chi^{2}(4, N=81)=1.459, p=.834$.

\section{Psychometric variables}

Table 3 shows the statistics from the questionnaires that the participants lilled in. Each variable was subjected to a oneway ANOVA to cstablish the statistical significance of the differences, as well as subsequently analyzing the direction of the effects. The results showed that the groups were statistically different in all the psychometric variables: BDi, $F(4,76)=$ $37.79, p<.001$, STAI-Trait, $F(4,76)=12.35, p<.001$; and STAI-State, $F(4,76)=9.24, p<.001$. For the BDI, as expected, the nonclinical groups (control and induction) oblained lower scores than the subclinical and clinical groups (MD and Dy). All the post Schefle comparisons between clinical versus nonclinical groups were statistically significant, $p<.001$.

For the STAl-Trait, control and induction groups were not statistically different, and neither were there statistical differences among the sutclinical, MD, and Dy groups. However, the 
Table 2

Stroop Stimuli (Spanish verion in brackets)

\begin{tabular}{|c|c|c|c|}
\hline \multicolumn{2}{|c|}{ ELATION } & \multicolumn{2}{|c|}{ DEPRESSION } \\
\hline Active [Activo/a] & Good [Bueno/al & Aloof [Retraído/a] & Nervous [Nervioso/a] \\
\hline Amusing [Divertido/a] & Happy [Feliz] & Boring [Aburrido/a] & Unsuccesstul [Fracasado/a] \\
\hline Brave [Valiente] & Healthy [Sano/a] & Coward [Cobarde] & Overworked [Agobiado/a] \\
\hline Calm [Tranquilo/a] & Interesting |Interesante] & Depressed [Abatido/a] & Oversensitive [Sensible] \\
\hline Charming [Encantador/a] & Lively [Animado/a] & Desperate |Desesperado/a| & Sad [Triste] \\
\hline Confidens [Contiado/a] & Nice [Agradable] & Embittered [Amargado/a] & Spiritless [Apagado/a] \\
\hline Contented [Contento/a] & Optimistic [Optimista] & Gloomy [Sombrío/a] & Tearful [Lloroso/a] \\
\hline Daring [Atrevido/a] & Resolute [Decidido/a] & He]pless [Indefenso/a] & Unfortunate [Desdichado/a] \\
\hline Efticient [Eficaz] & Satisfied [Satisfecho/a] & Sorrowful [Pesaroso/a] & Unhappy [Infeliz] \\
\hline Fortunate [Afortunado/a] & Sociable [Sociable] & Irresolute [Indeciso/a] & Finished [Acabado/a] \\
\hline Friendly [Simpático/a] & Strong [Fuerte] & Lonely [Solitario/a] & Sickly [Entermizo/a] \\
\hline Funny [Gracioso/a] & Vital [Enérgico/a] & Melancholic [Apenado/a] & Wretched [Desgraciado/a] \\
\hline Glad [Alegre] & & Miserable [Miserab]e] & \\
\hline
\end{tabular}

control group was statistically different from the subclinical, $p$ $<.005$, Dy, $p<.001$, and MD groups, $p<.001$; the induction group differed statistically from $\mathrm{Dy}, p=.003$, and from MD, $p=.013$, but not from the subclinical group, $p=.08$.

In the STAI-State, control and induction groups were not statistically different, and there were no statistical differences among the subclinical, MD, and Dy groups. The control group was statistically different from the subclinical, $p=.008$, Dy, $p=.007$, and MD, $p<.001$, groups. The induction group differed from $\mathrm{MD}, p=.017$ but not from the subclinical, $p=.194$, nor from the Dy group, $p=.258$.

\section{Stroop Task}

The aim of the Stroop task was to demonstrate the existence of attentional bias in depression towards emotionally congruent stimuli. This would be revealed in the various group response times, and for the different Stroop conditions. Table 4 offers the means and standard deviations of the response time (in milliseconds) for each group and each Stroop condition.

A repeated measures ANOVA Stroop x Group was carried out, with group as the between-variable and Stroop as the within-variable. The results showed that the main effect for Stroop was not significant, $F(1,76)=.06, p<.808$, which means that the response times in the different cmotional Stroop cards (elation and depression) were similar. However, the main effect of group was statistically significant, $F(1,76)=27.442$, $p<.0001$, that is, the clinical groups took longer to colorname the Stroop stimuli than the remaining groups. The interaction Stroop $x$ Group was also statistically significant, $F(1,76)=3.026, p<.023$, which means that the groups behaved differently, depending on the Stroop condition they

Table 3

Means and Standard Deviations of the Groups in the BDI and the STAI

\begin{tabular}{|c|c|c|c|c|c|c|c|}
\hline & & \multicolumn{6}{|c|}{ GROUPS } \\
\hline \multicolumn{2}{|c|}{ Instruments } & Control & Induction & Subclinical & Dy & $\mathrm{MD}$ & TOTAL \\
\hline \multirow[t]{2}{*}{ BDI } & $M$ & 9.08 & 8.18 & 22.36 & 23.71 & 28.33 & 17.04 \\
\hline & $S D$ & 3.93 & 5.36 & 3.01 & 7.23 & 9.66 & 10.35 \\
\hline \multirow[t]{2}{*}{ STAI-S } & $M$ & 14.71 & 19.29 & 29.55 & 27.76 & 32.80 & 23.45 \\
\hline & $S D$ & 6.66 & 9.71 & 15.90 & 12.75 & 9.43 & 12.55 \\
\hline \multirow[t]{2}{*}{ STAI-T } & $M$ & 23.21 & 26.53 & 38.36 & 41.59 & 40.07 & 32.60 \\
\hline & $S D$ & 10.44 & 11.01 & 6.34 & 10.97 & {$[1.13$} & 12.9[ \\
\hline
\end{tabular}

Note. $\mathrm{Dy}=$ dysthymia: $\mathrm{MD}=$ major depression; $\mathrm{BDI}=$ Beck Depression Inventory; STAI-S = State-Trait Anxiety Inventory (State); STAI-T = State-Trait Anxjety Inventory (Trait). 
Table 4

Means and Standard Deviations (in brackets) of Response Times (Measured in Milliseconds) in the Stroop Task

\begin{tabular}{lccccc}
\hline Stroop condition & \multicolumn{4}{c}{ GRouPs } \\
\cline { 2 - 6 } & Control & Induction & Suhcinical & Dystlymia & MD \\
\hline Depression & $4506(912)$ & $5045(889)$ & $5355(1067)$ & $6833(1126)$ & $9248(1595)$ \\
Elation & $4532(920)$ & $5259(977)$ & $5820(1668)$ & $6879(1165)$ & $8660(1263)$ \\
\hline
\end{tabular}

Nole. $\mathrm{MD}=$ major depression.

faced. The results of these analyses can be seen in Figure 1. An ANCOVA with repeated measures was carried out as well, in which the co-variables were age, the BDI, the STAI-S, and the STAI-T scores. We only include the results of the ANOVA, because there were no statistically significant effects, so that these variables were not considered relevant to attentional bias.

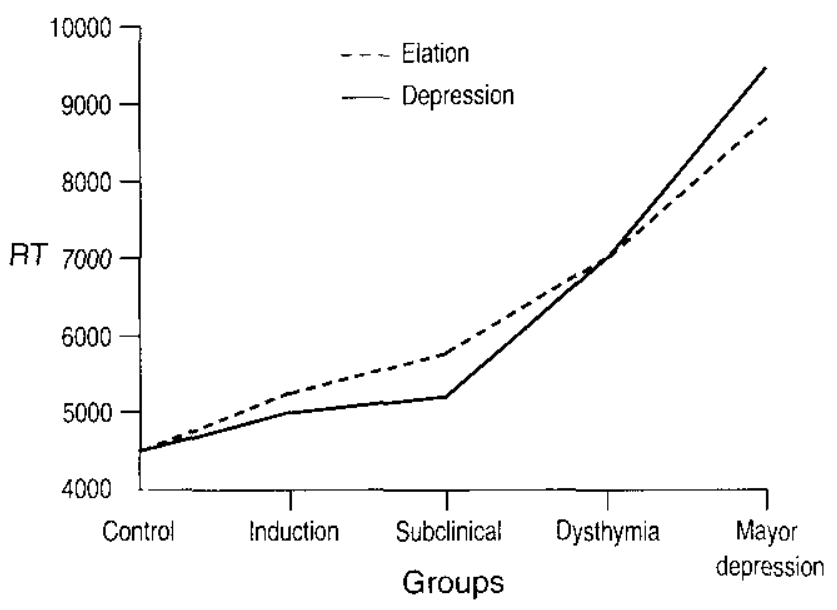

Figure 1. Response times (milliseconds) in the Stroop task.

Post-hoc multiple comparisons (Scheffé, $a=.05$ ) revealed that the MD group was significantly different from the rest of groups, $p<.001$, and from the Dy group. $p=.019$, in the elation condition. With regard to the Dy group, a signilicant difference with the control group appeared in both conditions, $p<.001$; a significant difference was also observed between the Dy and the induction groups in both conditions, $p<.05$.

\section{Discussion}

One of our aims was to find cvidence about the existence of attentional bias towards mood-congruent information in depressed individuals. The significance of the Stroop x Group interaction indicates that the groups behaved differently, depending on the Stroop condition they faced. However, only the MD group took longer to color-name the stimuli of the depression Stroop than those of the elation Stroop. The remaining groups showed the opposite result: participants were slower in the elation Stroop than in the depression Stroop. Nonetheless, the difference in the response times for each Stroop condition in the Dy and the control groups was barely evident. These data lend partial support to our first hypothesis: only the MD group showed significant emotional interference conceming negatively toned information. This is in accordance with the results obtained by Gollib and Cane (1987) who, using self-descriptive adjectives with cmotionally depressive content and emotionally manic content in their Stroop cards, found that the group of depressive patients, compared to the nondepressed group, obtained significantly higher response times for the depression words than for the clation words. Carter, Maddock, and Magliozzi (1992) found that individuals diagnosed as MD (DSM-III-R criteria), compared to a control group, showed just a trend (nonsignificant) towards greater interference in the depression Stroop. Segal and Vella (1990) applied a priming methodology to the Stroop task to examine cognitive organization in depression. They used a sample of patients with major depression (Research Diagnostic Criteria, RDC; Spitzer, Endicolt, \& Robins, 1978), who showed significantly more interference in the self-descriptive depression adjectives than in the neutral or personally irrelevant adjectives. These results suggested the existence of attentional bias in depression. However, in the study by Mogg et al. (1993), the emotional Stroop task was also administered to a clinical sample (diagnosis of MD and Generalized Anxicty Disorder, according to DSM-III-R criteria) and to normal subjects; the MD group did not show the Stroop interference effect in the depression words in cither of the Stroop conditions (subliminal and supraliminal). Therefore, our data support the majorty of studies that used samples of MD patients.

The second atm of our study was the issue of cognitive vulnerability to suller from depression. We wished to find out whether attentional bias constitutes a vulnerability factor capable of predisposing individuals to suffer from an episode of cepression in the future, or whether it constitutes another symptom of the disorder that only appears when the disorder is present. In order to answer this issue, we grouped our sample so the groups could be placed along a hypothetical continuum. At the lower end of this continuum would be those individuals with no emotional disorder (control group), followed by those 
presenting no clinical condition but who had undergone a mood induction procedure (induction group). Next would be the group of clinical analogues (subclinical group), that is, individuals with no clinical depression but whose high scores in the BDI allowed us to consider that they had not only the sad mood that is characteristic of depression, but also other signs and symptoms commonly present in the clinical form of the disorder. Finally, at the upper end of our continuum would be those individuals with a clinical diagnosis of dysthymia or major depression (Dy and MD groups). Using this continuum, we intended to discriminate at which point attentional bias (in the form of the Stroop interference effect) would appear. Depending on the result, we would obtain empirical support on the issue of attentional bias as a vulnerability factor for depression.

As stated, only the MD group showed significant interference in the depression Stroop. These results, therefore, do not support our hypotheses 2.2 and 2.3 : neither a simple sad mood nor a subclinical depression condition seems to reveal attentional bias for depression-related material, and thus we cannot state that bias is a vulnerability factor for depression. Furthermore, the subclinical and induction groups not only showed no bias towards the mood-congruent information, but they were also slower in color-naming the positive words than the negative ones. This trend leads us to examine the possibility of an avoidance bias towards negatively toned material in individuals with sad mood but no emotional disorder. In this sense, such a bias would "protect" them from processing this kind of aversive information.

Our data are, to some extent, different from those obtained in other studies. In Gotlib and McCann's (1984) work, the Stroop task was applied to two groups of individuals divided into depressed and nondepressed according to their score in the BDI (cutting point $\geq 9$ ); the depressed subjects obtained significantly greater response times for the words that were emotionally related to depression. To test whether the Stroop effect was simply because of the subjects' mood or other features, Gotlib and McCann induced a sad mood and a happy mood in a sample of normal participants. They verified that there were no group differences in the performance on the Stroop task for either positive or negative words. They concluded that the subjects' mood did not explain the Stroop interference effect sufficiently. Klieger and Cordner (1990) replicated this sudy to test whether the cognitive process present in depression could be assessed by the Stroop task; again, the response times were significantly greater in dysphoric individuals compared to nondysphoric ones (BDI criteria, cutting point $\geq 16$ ) for the negative depression-related words than for the positive ones. Our results with the subclinical group have not replicated those obtained in these studies. A possible explanation may be the different criteria of what is considered a subclinical depression score using the BDI. We chose a more conservative cutting point $(\geq 18)$.

Other studies about the influence of mood assessed attentional bias in depressed subjects during their depressive episode and after they had recovered. Gotlib and Cane (1987) found that attentional bias assessed with the Stroop task was only apparent when the patients were depressed and not once they had recovered. In the McCabe and Gotlib study (1993), although they used a dychotic listening task instead of the traditional Stroop, individuals were significantly slower in responding to light probes when negative-content words were presented in the unattended channel than when neutral-content words were presented. In the second session, recovered patients no longer revealed attentional biases. Given these results, it seems that there is attentional bias towards emotional, negatively toned material, although this bias is exclusively related to the clinical status of the disorder. These results suggest that the bias may be another symptom that would only appear when the disorder is present.

Nonetheless, the bias did not appear in our Dy group. This result, contrary to what has just been stated, could be explained by means of the hypothesis of "depressive realism" (e.g., Alloy \& Abramson, 1979, 1988). This hypothesis states that depression is characterized by a lack of bias towards positive information which, however, is present in nondepressed people and whose function is to act as a protection factor against depression. Furthermore, it has been suggested that these biases may be a function of the severity of depression, and that when people become mildly depressed (which would be the case of dysthymia), they exhibit unbiased cognitive functioning, but when depression becomes more severe (which would be the case of major depression), these people may show biases favoring negative information. Our results support this hypothesis, because they suggest that the clinical severity of the disorder is the factor playing the mayor role in the manifestation of attentional bias to mood-congruent negative information. However, our data are not in accordance with the "depressive realism" hypothesis, because the control group would be expected to show bias favoring positive material, but their performance was quite similar to that of the Dy group, as can be seen in Figure 1. This lack of "positive biases" in the emotional Stroop task in normal populations is quite a common result in literature. In fact, considering the response times obtained in other studies, people with no clinical disorder show no differences in their response times to positive and negative words (there are even studies in which these people are slower in color-naming the negative words compared to the positive words). Nonetheless, no study explicitly comments on this fact, except the work by Gotlib and McCann (1984). These authors pointed out that "positive biases" would only be expected in tasks involving threat to the subject's ego, which is not the case of the emotional Stroop task. Therefore, the absence of longer response latencies to positive words in the "normal" individuals lends weight to this motivational formulation. On the other hand, it could be that people with no disorder, when confronted with sadness (induction and subclinical groups), "protect" themselves against it by avoiding negative and favoring positive material. In this case, 
they set up "self-protective biases." This self-protection may have a varicty of adaptive consequences, such as maintaining positive affect, self-esteem, and improving coping stratcgies, as well as reducing the likelihood of hopelessness. Such a mechanism was not observed in the Dy group which, although sad (in contrast to the control group), did not show any tendency 10 avoid negative information nor to protect themselves against it (in contrast to the subclinical and induction groups). However, in the MD group, this tendency was the opposite, revcaling altentional bias in favor of negative over positive information.

It is important to bear in mind that there are several factors that could influence the incidence of attentional bias. The small size of the sample could disguise the effects of bias. The studies by Gotlib and Cane (1987), and Catter et al. (1992) employed larger samples ( 34 and 30 patients with MD, respectively) than other studies, including ours, where the number of individuals in the various groups ranged from 11 to 25 . This is an important issue because sometimes the nonsignificance of the differences is duc to the inadequate size of the samples, and this does not necessarily mean that bias does not exist. Even more important is the issuc of which subjects to include in the samples. We have observed high variability and disparity of critcria in the design of groups, especially regarding clinical analogues. The cutting point that divides subjects with subclinical depression from the nondepressed varies greatly: $\geq 9$ in Gotlib and McCann (1984), $\geq 16$ in Klieger and Cordner (1990), $\geq 10$ in Hill and Dutton (1989), and $\geq 18$ in our own study. Besides, inventories other than Beck's have been used, such as the lnventory to Diagnose Depression (IDD: Zimmerman, Coryell, \& Wilson, 1986) in Hill and Knowles' (1991) study. The use of poor emotional measures and, especially, of inadequate pools of stimuli are also important aspects to be considered when analyzing data. Greenberg and Beck (1989) stated that there is a specificity of content for depression that would differentiate the cognitions of depressed subjects from those of anxious subjects: the predominant themes in depression are self-contempt, failure, incompetence, and pessimism. Anxiely focuses on threat, danger, unpredictability, and uncertainty. The stimuli used in the Stroop task when studying attentional biases in depression have not always been the most appropriate. Sometimes, the stimuli were self-esteem threatening words (Hill \& Dutton, 1989; Hill \& Knowles, 1991), physically threatening words (Carter et al., 1992; MacLeod et al., 1986), socially threatening words (MacLeod et al.), and achievement theatening and general threatening words (Mogg et al., 1991). We think, along with Hill and Knowles (1991), that the use of emotional stimuli is essential, so that the Stroop interference effect will appear. The pool of stimuli used in the cutrent paper adheres to this critcrion. Another important difference between our study and those cited above is that we compared five groups simultaneously, whereas the remaining studies just compared two groups, which could hinder reaching clear conclusions about the role that attentional biases may play in vulnerability towards depressive disorders.

Summing up, we found attentional bias to the moodcongruent material in depression only when this disorder turned into major depression. The bias did not appear in milder but more chronic forms of the disorder, such as dysthymia. Finally, according to our results, it scems that the bias is limited to depression as a clinical entity, and it does not seem to constitute a cognitive vulnerability factor because it was not present in our analogue groups. Nor did bias seem to be a result of a simple sad mood. Nevertheless, more studies, using different clinical conditions, are needed in order to state with some degrec of certainty to what extent attentional biases do, or do not, constitute a cognitive vulnerability factor in depression.

\section{References}

Alioy, L.B., \& Abramson, L.Y. (1979). Judgement of contingency in depressed and nondepressed students: Sadder but wiser? Journal of Experimental Psychology: General. 108, 481-485.

Alloy, L.B.. \& Abramson, L.Y. (1988). Depressive realism: Four theorctical perspectives. In L.B. Alloy (Ed.), Cognitive processes in depresion (pp. 223-265). New York: Guilford l'ress.

American Psychiatric Association (1987). Diagnossic and statistical manual of mental disorders ( $3^{\text {rd }}$ ed. revised). Washington, DC: Author.

American Psychiatric Association (1994). Diagnostic and statistical manual of mental disorders (4th ed.). Washington, $\mathrm{DC}$ : Author.

Beck. A.T. (1967). Depression: Clinical experimental and theoreticat aspects. New York: Hocber.

Beck. A.T. (1976). Cognitive therapy and the onotional disorders. New York: International University Press.

Beck. A.T. (1987). Cognitive models of depression. Jonmal of Cognitive Psychotherepy. $1,5-37$.

Beck, A.T., Rush, A.J., Shaw, B.F., \& Emery, G. (1979). Cognitive sherapy of depression. New York: Guilford Press. (Spanish Iranslation: Terapia cogniniva de la depresion. Bitbio: Desclée de Brouwer, 1983).

Carter. C.S., Madtlock, R.J., \& Magilozzi, J. (1992). Patterns of abnormal processing of emotional information in panic disorder and major depression. Psychomothology, 25, 65-70.

Cassidiy. K.L., McNally R.J, \& Zeitlin, S.B. (1992). Cognitive processing of trauma cues in rape victims with post-traumatic stress disorder. Cognitive Therapy and Research, 16, 283-295.

Dalgleish. T. \& Wats, F.N. (1990). Biases of atemion and memory in disorders of anxicty and depression. Cinical Psvchological Revien: $10.589-604$.

Foa. E.B., \& McNally. R.J. (1986). Sensitivity to feared stimuli in obsessive-compulsives; A dichotic listening analysis. Cognitive Therapy and Research, 10, 477-486.

García-Patacios. A. (1995), Induccion experimental del estado de animo: variables moduladoras y cuestiones mesodológicas. 
Unpublished 1st degree dissertation. Universitat Jaume I, Castellón, Spain.

Gotlib, J.H. \& Cane, O.B. (1987), Constnet accessibility and clinical depression: A longitudinal investigation. Journal of Abnormal Psychology: 96, 199-204.

Gotlib, I.H., \& McCann, C.D. (1984), Construct accessibility and depression: An examination of cognitive and affective factors. Journal of Personality and Social Psychology, 47, 427-439.

Greenberg. M.S., \& Beck, A.T. (1989). Depression versus anxiety: A test of the content specificity hypothesis. Jounal of Alnomal Psychology, 98, 9- $[3$.

Hill. A.B., \& Dutton. F. (1989). Notes and shonter communications: Depression and selective attention to self-estecm threatening words. Personality and Indwidual Differences, 10, 915-917.

Hill, A.B., \& Knowles, T.H. (1991). Depression and the "emotional" Stroop effect. Personality and Individad Differefuces, 12,481 485.

Hope D.A., Rapee, R.M., Heimberg, R.G., \& Dombeck, M.J. (1990). Representations of the self in social phobia: Vulnerability to social threat. Cognitive Therapy and Research, 14, 477-485.

Kaspi, S.P., McNally, K.J., \& Amir, N. (1995). Cognitive processing of emotional information in posttraumatic stress disorder. Cognitive Therapy and Research, 19, 319-330.

Kenealy, P.M. (1986). The Vclten mood induction procedure: A methodological review. Motivation and Emotion, 10, 315-335.

Klicger. D.M. \& Cordner. M.D. (1990). The Stroop task as a measure of construct accessibility in depression. Personality and Individual Differences, 11 , 19-27.

Larsen R.J., \& Sinnet, L.M. (1991). Meta-Analysis of experimental manipulations: Some factors affecting the Velten mood induction procedure. Personality and Social Psychology Bulletin. 17, 323334.

Lavy, E., van den Hout, M., \& Arntz. A. (1993). Attentional bjas and spider phobia: Conceptual and clinical issues, Behaviour Research and Therapy, 3I, 17-24.

Lavy, E., van Oppen, P. \& van den Hout. M. (1994). Selective processing of emotional information in obsessive-compulsive disorder. Behaviour Researh and Therapy, 32, 243-246.

MacLeod, C., Mathews, A., \& Tata, P. (1986). Attentional bias in emotional disorders. Joumal of Abnomal Psychology, 95, 15-20.

Martin. M.(1990b). Cognitive biases in anxiety. In P.J.D. Drenth. J.A. Sergent, \& R.J. Takens (Eds.), European perspectives in psychology. New York: Wiley.

Martin, M., Argyle, M., \& Crossland, J. (1990). A trouble shared is a trouble hahed: Social and solitary, positive and negative mood induction. Manuscript submitted for publication.

Martin, M., Williams, R.M. \& Ciark, D.M. (1991). Docs anxjety lead to selective processing of threat-related information? Behaviour Research and Therapy, 29, 147-160.

Mathews, A. Mogg. K., Kentish, J., \& Eysenck, M. (1995). Effect of psychological treatment on cognitive biases in generalized anxiety disorder. Behawow Researh and Therapy, 33, 293-303.

Mathews, A.M.. \& Sebastian, S. (1993). Supression of emotional Stroop effects by fear arousal. Cognition and Emotion, 7, 517530 .
Mattia, J.I., Heimberg, R.G. \& Hope, D.A. (1993). The revised Stroop colour-naning task in social phobics. Behaviour Research and Therapy, 31, 305-314.

McCabe, S.B., \& Gotlib, I.H. (1993) Attentional processing in clinically depressed subjects: A longitudinal investigation. Cognitive Therapy and Research, 17, 359-377.

McNally, R.J., Amir, R.. Louro. C.E., Lukach, B.M., Rienmann. B.C., \& Calamari, J.E. (1994). Cognitive processing of idiographic emotional information in panic disorder. Behaviour Research and Therapy, 32, 119-122.

McNally, R.J., English, G.E., \& Lipke, H.J. (1993). Assessment of intrusive cognition in PTSD: Use of the modified Stroop paradigm. Journal of Traumatic Stress, 6, 33-41.

McNally, R.J., Rienmann, B.C.. \& Kim, E. (1990). Selective processing of threat cues in post-traumatic stress disorder. Journal of Abnormal Psychology, 99, 398-402.

Mogg, K., Bradley. B.P., Williams, R. \& Mathews, A. (1993). Subliminal processing of enotional information in anxiety and depression. Joumal of Abnomal Psychology, 102, 304-311.

Mogg. K., Mathews. A.. May, J., Grove, M., Eysenck, M.. \& Weinman, J. (1991). Assessment of cognitive bias in anxiety and depression using a colour perception task. Cognition and Emotion, 5, 221-238.

Ruipérez, M.A. \& Belloch, A. (1997). Depresión y autoesquemas depresivos en pacientes deprimidos y ansiosos. Revista de Psicopatologia y Psicología Clínica, 2, 65-80.

Segal, Z.V., \& Vella, D.D. (1990). Self-Schema in major depression: Replication and extension of a priming methodology. Cognitive Therapy and Research, 14, 161-176.

Spielberger, C.D. (1983). Manual for the State-Trait Anxiety Imentory (Reved.). Palo Alto. CA: Consulting Psychologists Press.

Spitzer, R.L., Endicott, J. \& Robins, E. (1978). Research diagnostic criteria for a selected group of functional disorders. New York: New York Psychiatric Institute.

Stroop, J.R. (1935). Studies of interference in serial verbal reactions. Joumal of Experimental Psychology, 18, 643-662.

Velten, E. (1968). A laboratory task for induction of mood states. Behavior Research and Therapy, 6, 473-482.

Watts, F.N., McKenna, F.P., Sharrock, R., \& Trezise, L. (1986). Colour naming of phobia-related words. British Journal of Psychology, 77, 97-108.

Williams, J.M.G., Watts, F.N., MacLeod, C., \& Mathews A.M. (1988). Cogritive psychology and enotional disonders. Chicester. UK: Wiley.

Williams, J.M.G., Watts, F.N., MacLeod, C., \& Mathews A.M (1997). Cognitive psychology and enotional disorders ( $2^{\text {nd }}$ ed.). New York: Wiley.

Zimmerman, M., Coryell, W., \& Wilson, S. (1986). A self-report scale to diagnose major depressive disorder. Archives of General Psychiatry, 43, 1076-1081.

Received September 18, 1998 Revision reccived December 23, 1998 Accepted March 3, 1999 